\title{
Epilepsy in Elderly
}

Qing Zhao' ${ }^{1,2}$ and Jin Jun Luo ${ }^{1,3 *}$

${ }^{1}$ Department of Neurology, Temple University School of Medicine, 3401 North Broad Street, Suite C525, Philadelphia, PA 19140, USA

2Linzi District Maternal and Child Health Hospital, 123 Dashun Road, Linzi,Zibo, Shandong, PR 255400, China

${ }^{3}$ Department of Pharmacology, Temple University School of Medicine, 3401 North Broad Street, Suite C525, Philadelphia, PA 19140, USA

*Corresponding author: Luo JJ, Departments of Neurology and Pharmacology, Temple University School of Medicine, 3401 North Broad Street, Suite C525, Philadelphia, PA 19140, USA, Tel: 1-215-707-3040; Fax: 1-215-707-8235; E-mail: jluo@temple.edu

Rec date: Dec 27, 2013, Acc date: Mar 12, 2014, Pub date: Mar 17, 2014

Copyright: ( 2014 , Luo JJ et al. This is an open-access article distributed under the terms of the Creative Commons Attribution License, which permits unrestricted use, distribution, and reproduction in any medium, provided the original author and source are credited.

\begin{abstract}
Advanced technology and life science significantly prolongs human's lifespan. The prolonged longevity enables people to enjoy longer life but adversely increases the mortality and morbidity of aging-related disorders which may, in turn, devalue the quality of late life. Of the aging-related neurological conditions, increased incidence and prevalence of convulsive disorders, namely seizures or epilepsies, have been documented in literature. Epilepsy is the third most common neurological condition after dementia and stroke among the elderly. Multiple risk factors cause the elderly to be prone to develop seizures or epilepsies, including advanced aging, stroke, traumatic brain injury, dementia, neurodegenerative diseases, brain tumors, obstructive sleep apnea, and obesity. In this article, we highlight the epidemiology, pathophysiology, and clinical manifestations of elderly seizures.
\end{abstract}

Keywords: Epilepsy; Seizure; Elderly; Senior; Risk factor

\section{Introduction}

Advanced civilization promotes longevity of human being. The term of senior, or elderly, is defined as a person over the age of 60-65 years and retired [1,2]. In 2010, 40 million people aged 65 and over accounted for 13 percent of the total population in the United States. The number and proportion of older Americans is expected to grow significantly to 72 million in 2030 , representing nearly 20 percent of the population. The population aged 85 and over was 5.5 million in 2010 and will grow to 19 million by 2050 [3]. Although the prolonged lifespan enables people to enjoy longer lives, it also simultaneously generates many age-related health problems. Occurrence of convulsive disorders, namely seizures, is significantly increased in the elderly.

\section{Seizure and Epilepsy}

Seizure is a devastating but treatable medical condition caused by an abnormal paroxysmal time-limited hypersynchronous electrical discharges of the brain cortical neurons, manifesting as motor, sensory, and/or autonomic dysfunction with or without loss of consciousness. Epilepsy is a chronic disorder of the central nervous system (CNS) whose symptoms are recurrent seizures. Most new seizures in elderly patients are localization-related, termed as focal seizures with or without secondary generalization, such as simple or complex partial seizures, once commonly known as petit mal seizures. A simple partial seizure doesn't result in loss of consciousness but cause involuntary jerking movement of a body part, i.e. an arm or a leg; or sensory symptoms, such as tingling, dizziness and flashing lights. A complex partial seizure, previously termed temporal lobe or psychomotor seizure, results in alteration or loss of consciousness. Localization-related epilepsies are manifested with focal deficits resulting from specific functions of the respective brain areas. The location of neuropathology underlying epilepsy determines the manifestation of seizures. For example, temporal lobe pathology can cause epilepsy with memory impairment; while pathology involving the language-dominant hemisphere may produce word finding and naming difficulties; and certain epilepsy syndromes are associated with severe cognitive or behavioral problems [4-6]. The generalized seizures in elderly, in contrast to $50 \%$ seen in children under the age of 15 , are only seen in $25 \%$ of senior epileptic patients and usually occur following an anoxic insult [7-11]. They usually present as tonic-clonic convulsions, which were once commonly known as grand mal seizures. They may also evolve from localization-related seizures as the secondary generalization. Rarely, absence status epilepticus may occur in elderly, which can be caused by transient metabolic or toxic derangement such as benzodiazepine withdrawal, however, it usually does not need long-term antiepileptic medications [12].

A provoked seizure is an acute symptomatic episode that occurs in close temporal relation with the insult such as stroke, traumatic brain injury (TBI), or an otherwise obvious insulting metabolic or toxic attack which is presumed to be the underlying cause. In contrast, an unprovoked seizure occurs in the absence of one or any precipitating factors, and it includes events occurring in patients with antecedent stable (nonprogressing) (CNS) insults, or remote symptomatic seizures [13]. The definition of onset of an acute symptomatic seizure can be divided into two subtypes: early-provoked seizures as the events occurring within the first 7 days after a CNS insult, and late-provoked seizures as those occurring 7 days later. While an unprovoked seizure occurs in the absence of any precipitating factors, unprovoked epilepsy is the occurrence of repeated unprovoked seizures [14]. Status epilepticus is continuous seizures lasting 30 minutes or longer; or two or more discrete seizures between which there is incomplete recovery of consciousness $[15,16]$. 


\section{Epidemiology}

Epilepsy affects approximately 50 million people worldwide [17] including approximately 300,000 seniors in the United States. Epilepsy is frequently seen in the elderly [18]. The annual incidence of epilepsy increases from $110 / 100,000$ people between the ages of 65 and 69 to more than $160 / 100,000$ in those over 80 years [10,19-21]. In individuals aged 65 years or older, dementia and other neurodegenerative diseases account for $9-17 \%$ of the causes for epilepsies [10,18,22-27]. By 75 years of age, $3 \%$ of the population will likely have epilepsy and $10 \%$ will have had a seizure of some type. In contrast, only $1 \%$ will have developed epilepsy by age 20 [28]. The annual incidence in population over the age of 60 years increased from 1.04 per 1,000 in people $65-69$ years-old to 3.58 per 1,000 in those 85 years [7,27,29-34]. Epilepsy is the third most common neurological condition after dementia and stroke among the elderly [31].

Older adults are the fastest growing population group with epilepsy. Increase in prevalence of epilepsy among older adults may be due to multiple comorbidities that older adults frequently experience. For example, elderly are at an increased risk of stroke and heart attack, both of which can damage the brain and cause epilepsy. Indeed, stroke is the most common cause of seizures in elderly, causing about 33 percent of all cases of epilepsy. Elderly are also at risk for dementia, including Alzheimer's disease (AD), which is the second most common cause of epilepsy in seniors. In addition to their underlying medical conditions such as hypertension, atherosclerosis, and metabolic disorders with organ failures; traumatic brain injury (TBI) after a fall due to imbalance or weakness from peripheral neuropathy is also a significant risk factor. These medical conditions may damage the brain and result in seizures.

The most common etiologies for seizures in the elderly are cerebrovascular disease, toxic and metabolic encephalopathies, dementia, and brain tumors $[23,24]$. In patients with dementia, the incidence of seizures is 5-10 times greater than that in a reference population, and 10 to $22 \%$ of $\mathrm{AD}$ patients have at least one unprovoked seizure [35]. Patients with a combination of stroke and dementia were at a significant higher risk for development of epilepsy than patients with either a stroke or dementia alone [36].

The incidence of epilepsy increases with age after 60 years [37]. Almost 25\% newly diagnosed epilepsies are over 60 years old. Epilepsy is a significant comorbidity in the elderly after stroke and dementia [38]. Both unprovoked and acute symptomatic seizures are common in the elderly. The incidence of any type of first seizure is 50/100,000 people aged 40-59 years, and increases to $127 / 100,000$ in those older than 60 years [22]. The prevalence steadily increases with age and is estimated to be $5 / 1,000$ between 20 and 50 years, 7/1,000 between 55 and 64 years and 12/1,000 between 85 and 94 years [23]. The estimated prevalence of epilepsy may be higher ranging from 13 to 50 per 1,000 depending on the population studied [22,39-41] and the estimated incidence ranges from 1.0 to 2.6 per 1,000 depending on age [10,42]. A recent study showed that prevalence of epilepsy in elderly is estimated 10.8 per 1,000 and the incidence of new-onset epilepsy is estimated 2.4 per 1,000 [43]. Prevalence and incidence rates were highest among African Americans, particularly African American men, which is consistent with earlier reports $[44,45]$. African Americans had almost twice the prevalence $(18.7$ per 1,000$)$ and incidence $(4.1$ per 1,000$)$ than Caucasians (10.2 prevalence, 2.3 incidence), while Asians (5.5 prevalence, 1.6 incidence) and Native Americans (7.7 prevalence, 1.1 incidence) had lower rates. Incidence rates were slightly higher for women than for men, and increased with age for all gender and race groups. In contrast to the previous studies of higher prevalence and incidence in men [44,45], however, Faught and colleagues reported that men and women had similar prevalence and incidence [43].

\section{Etiologies and Risk factors for Seizures in Elderly}

\section{Stroke}

Stroke is an aging related disorder although it also affects youths. A recent report estimated approximately 795,000 Americans experience a stroke every year, which approximates to 1 stroke every 40 seconds [46]. In the United States, the most common cause of provoked seizures in elderly people is acute stroke [29,47-49]. Eight percent of patients will develop seizures within two weeks of a hemorrhagic stroke, compared with $5 \%$ among those who have had an ischemic stroke. Previous stroke occurrence is the most common underlying etiology, accounting for $30-40 \%$ of all cases of epilepsy. Asymptomatic cerebral infarction can also lead to epilepsy and, reciprocally, seizures may be a marker of increased risk for subsequent stroke [50]. The frequency of poststroke seizures varies from $2.3 \%$ to $4.5 \%$ [7,51,52]. In a long-term prospective controlled study of 484 patients with ischemic strokes, Lossius and colleagues reported that the prevalence of poststroke epilepsy was $3.1 \%$ in 7 to 8 years after an ischemic stroke. The occurrence has been shown to be related to the severity of stroke and worse Stroke Scale scores on admission, which is considered as a significant predictor for poststroke epilepsy $[53,54]$. In addition to the severity of a stroke, factors such as hemorrhagic stroke, cortical location of the stroke [53,55-60]; and late onset of the first seizure after a stroke [55,61-65]; have been found to predict poststroke epilepsy. Interestingly, age at stroke onset has not been found to predict poststroke epilepsy [66].

Seizures were more common in lobar hemorrhages but subcortical hemorrhages were found to be linked often with secondary generalization [67]. Occurrence of posthemorrhagic seizures was associated with neurologic worsening on the NIH Stroke Scale and with an increase in midline shift. In a prospective study on patients with ischemic stroke $(n=46)$ and intraparenchymal hemorrhage $(\mathrm{ICH})$ $(n=63)$ with continuous electroencephalograph (EEG) monitoring for 72 hours after admission, Vespa and colleagues observed that electrographic seizures occurred in $28 \% \mathrm{ICH}$ patients, compared with $6 \%$ ischemic stroke $(\mathrm{OR}=5.7,95 \% \mathrm{CI}: 1.4$ to $26.5, \mathrm{p}<0.004)$ and there was a trend toward increased poor outcome [67]. It is evidenced that stroke is the most common risk factor for seizures in the elderly population accounting for $39-45 \%$ of all seizures [68-70]. Pre-existing dementia increases the risk of late seizures after stroke (occurring more than 7 days after stroke) but not of early seizures (occurring within 7 days of stroke onset) [32].

\section{Traumatic brain injury}

Elderly are at increased risk for TBI, which is an important factor to cause seizure and epilepsy because of elderly's pathophysiologic conditions and prone to falls. Post-traumaticepilepsy (PTE) is a recurrent seizure disorder following a head trauma. It can occur immediately or years after the brain injury. In a recent populationbased study of 2,118 patients hospitalized with TBI, 115 (5.4\%) developed epilepsy in 2-3 years following hospital discharge [71]. A previous study indicated that up to $20 \%$ elderly epilepsy can be caused by TBI [72]. PTE accounts for approximately $20 \%$ of symptomatic epilepsy in the general population and $5 \%$ of all epilepsy patients [73-76]. 
Increased TBI severity increases risk of late posttraumatic seizures (PTS) or PTE [73,77-79]. Notably, early PTS may be a risk factor for late seizures or epilepsy in adults [77,80,81]. Findings of $26 \%$ of hospitalized TBI cases with early PTS progressing to unprovoked seizures in a 10-year retrospective study suggested that seizures are an important neurologic complication of TBI [82]. A prospective study of hospitalized adults with TBI in Europe showed early PTS is the strongest risk factor for PTE [83]. Interestingly, there was no difference in risk of PTE by gender [71,83] and race [71] but higher prevalence of epilepsy among individuals aged 45-64 years and those with lower education and income as shown in a population-based study [84]. Seizures following TBI have been reported as more common in elderly [73]. The reported overall incidence of late PTS or PTE has a range of $13-50 \%$, depending on the population studied and the follow-up time, with the highest incidence coming from studies of war veterans, among whom penetrating TBI is more common than among civilians [77,78,80,81,83,85-87].

The precise mechanism by which a trauma to the brain tissue leads to recurrent seizures remains unknown but the resultant cortical dysfunction plays an important role in the genesis of the epileptic activity. Pathogenesis of causing early seizures likely differs from that of causing late seizures [88-90]. Subdural hematoma is a potentially treatable cause of epilepsy in elderly people. Interestingly, clinical observation suggests that the treatment of early PTS does not influence the incidence of late PTS or PTE, therefore, routine prophylactic administration of anticonvulsants is not recommended for patients with head injuries, and treatment in the acute phase does not reduce death or disability rates [91-99]. However, according to the latest guidelines issued by the Brain Trauma Foundation, the American Academy of Neurological Surgeons (AANS), and Congress of Neurological Surgeons (CNS) for the management of severe TBI, seizure prophylaxis is recommended during the first seven days after TBI (level II) [100].

\section{Dementia and neurodegenerative diseases}

Age is a common risk factor for both epilepsy and dementia. The prevalence of dementia is estimated approximately $6-8 \%$ after 65 years of age and may rise to $20-30 \%$ in individuals older than 85 years [101-103]. Strong evidence from ample clinical studies has been shown that seizures are more frequently seen in Alzheimer's disease (AD) patients than in the general population [25,104-107]. $\mathrm{AD}$ is a progressive neurodegenerative disorder and is the most common cause of dementia among older people. Patients with $\mathrm{AD}$ are up to ten times more likely to develop epilepsy than those without $\mathrm{AD}[25,108]$ and seizures usually develop in the advanced stage [70]. Advanced AD alone is an important risk factor for late-onset seizures $[105,107,109,110]$. Epilepsy in dementia has significant consequences on the prognosis of the underlying dementia. Seizures worsen cognitive performance, particularly in language, and compromise autonomy leading to an increased risk for injury and mortality rate [111-113]. Language functions declined more rapidly in AD patients with seizures than in those without seizures matched by age and duration of AD [111-113]. Additionally, these patients are vulnerable to the adverse effects of medications and their conditions may suddenly worsen and require an admission to a long-term care facility within 6 months of the seizure onset [113-116].

Although $\mathrm{AD}$ is the most common form of dementia, other causes include vascular disease, Lewy body disease, and frontotemporal lobe dementia [117]. Dementia has been estimated to account for $10-20 \%$ of all epilepsies in elderly [118]. Ironically, younger age is a risk factor for seizures in dementias [106,107]. The overall incidence of unprovoked seizures in $\mathrm{AD}$ is higher than in age-matched general population (hazard ratio, 8.06; 95\% confidence interval, 3.23-16.61). A proportion of 2 to $13 \%$ of $\mathrm{AD}$ patients would have a seizure within 5 years of dementia diagnosis [107]. $\mathrm{AD}$ and other dementias are associated with a 5-10 fold increase in risk of epilepsy when compared with the control population $[119,120]$ and, by the tenth year after diagnosis, $15 \%$ diagnosed $\mathrm{AD}$ patients will develop epilepsy [25,119]. Amatniek et al. [106] evaluated the cumulative incidence of $\mathrm{AD} /$ seizures and identified comorbid medical and psychiatric baseline conditions that could influence the risk of an unprovoked seizure in patients with mild AD. They found the cumulative incidence of unprovoked seizures at 7 years was almost $8 \%$. Independent predictors of unprovoked seizures are younger age, African-American ethnic background with severe dementia and focal epileptiform activity on EEG. Additionally, seizures are more likely to occur with early-onset disease, particularly in the familial form with presenilin-1 mutation [121-124]. However, controversies exist. No association between seizures and patient age at the onset of $\mathrm{AD}$ nor between seizures and any prior EEG findings were also noted [105]. Compared to AD patients without seizures, $\mathrm{AD}$ patients who had seizures were not different in other medical conditions, the medications they took, or the degree of focal pathology $[105,125]$.

Generalized tonic-clonic seizures are common in $\mathrm{AD}$ patients which have presumably been evolved secondarily from a partial seizure focus $[108,125,126]$. Complex partial status epilepticus [111] and myoclonus [126] have infrequently been encountered. EEG is a useful tool aiding in the diagnosis. In a VA cooperative study including EEGs, which enrolls patients who are 60 years and older with new-onset epilepsy and excludes patients with progressive neurologic conditions (including dementia and primary brain tumors), epileptiform activity was present in $37 \%$ of routine EEG [127]. In a study of 254 patients with $\mathrm{AD}$, Smits and colleagues reported significant EEG abnormalities were associated with different cognitive profiles in AD. Only $28 \%$ of these patients had a normal EEG, while $32 \%$ had focal abnormalities, $14 \%$ diffuse abnormalities and $26 \%$ had both focal and diffuse abnormalities [128]. Seizure incidence is increased in people starting with mild-to-moderate AD. Younger individuals, African Americans, and those with severe dementia or focal epileptiform findings on EEG were more likely to have unprovoked seizures [106]. However, Liedorp and colleagues reported epileptiform discharges were seen in only $3 \%$ (42 of 1,674) patients with $\mathrm{AD}$ and other forms of dementia on routine EEGs, suggesting the rate was very similar to those of the general population [129]. The discrepancy in EEG findings may be due to multifactors, including variations in EEG acquisition, such as length of recording, appropriate montage; use of medications among the other factors [130-134] and even the oily scalp may affect the recording. In fact, a focal slow, such as delta, activity can be considered relevant to be epileptic in elderly due to a focal deep white matter pathology, however, temporal slow-wave activity may be a normal consequence of aging $[135,136]$.

The nature of the underlying mechanism for unprovoked seizures in $\mathrm{AD}$ remains unclear. Hippocampal neuronal degeneration is the most common abnormal lesion identified in temporal lobe epilepsy and it has been reported in many different dementias, including AD, dementia with Lewy bodies or fronto-temporal dementia [137]. Mutations in the $\alpha$-synculein gene that are associated with hereditary Parkinson's disease and Pick's dementia have also been shown to have 
an increased risk for the development of progressive myoclonic epilepsy with generalized tonic-clonic seizures [138]. Longitudinal clinical follow-up in patients with EEG, SPECT and CSF biomarkers suggested an underlying encephalopathy with cortical involvement [139]. The role of a disproportionate neuronal degeneration in the parietal and hippocampal areas has been postulated to be the neuropathological substrate of seizures in AD [110]. A relationship between cell loss in the CA1 area of the hippocampus with a high density of $A \beta$ plaques and neurofibrillary tangles, and the occurrence of seizures has been postulated in patients with familial AD. In mouse $\mathrm{AD}$ models, constituents of amyloid- $\beta$ (A $\beta)$ plaques deposited in hippocampal circuits have been demonstrated to be epileptogenic $[140,141]$. The role of the accumulation of $A \beta$ plaques, neurofibrillary tangles and extensive neuronal cell loss in limbic and association cortices has been suspected [35]. The accumulation of $A \beta$-plaques may also play a role in epileptogenesis for seizures as in the cases of $A \beta-$ related angiitis [142]. Animal studies have demonstrated that introduction of high levels of $A \beta$ is sufficient to elicit epileptiform activity in vivo in the absence of frank neurodegeneration [143,144], which suggests that the primary effect of $A \beta$ in provoking a seizure is due to aberrant network synchronization, rather than a secondary consequence of extensive neurodegeneration [140,143]. Additionally, neuronal loss in $\mathrm{AD}$ may consequently affect GABAergic inhibitory circuits and the balance between excitation and inhibition which may induce seizures [125]. An alternative to the role of histopathological lesions could be the selective loss of inhibitory neurons which may facilitate the occurrence of seizures [125]. The aberrant excitatory neuronal activity represents a primary upstream mechanism that may contribute to the epileptogenesis in $\mathrm{AD}$ [140].

\section{Brain tumors}

Brain tumors are a recognized risk factor for epilepsy in elderly people [70]. More than 17,000 people in the United States are diagnosed each year with a brain tumor. An estimated $10 \%$ to $20 \%$ of seizures are associated with tumors while brain tumors have been found in $32.9 \%$ of the elderly patients [7,22,27,145-147]. Seizures might be the first symptom of, and particularly common with, slowgrowing tumors. Approximately $30 \%$ to $50 \%$ of brain tumor patients may have a seizure by the time their tumors are diagnosed, and an additional $6 \%$ to $45 \%$ of patients who do not initially present with seizures would eventually develop them [148-150]. Characteristics of brain tumors and their mechanisms in causing seizures in patients are incompletely understood $[149,151]$.

Frequently associated with seizures are low grade well-differentiated gliomas [151-155], cortically located tumors [148,156-159], particular location in the temporal or frontal and motor or sensory cortices $[151,160,161]$. The most common types of brain tumors that are found to produce seizures in later life are gliomas, meningiomas and metastases [147], especially located in the convexity of the brain. Meningioma is known to be one with a higher incidence of epilepsy $[162,163]$. Notably, rapidly growing tumors, such as high-grade gliomas, particularly those situated in deeper structures, usually present with non-seizure-related symptoms. Patients with high-grade tumors in the pericallosal region, such as glioblastoma multiforme, were significantly less likely to present with seizures, even the highgrade tumors in the temporal lobe [164]. While low-grade gliomas, such as those located in the temporal lobe or the insula grow large without other symptoms and eventually cause seizures [164]. Patients with low-grade tumors were more likely to present with seizures if their tumors were situated in the temporal lobe or in the insular cortex. In other words, rapidly growing tumors cause symptoms related to mass effect, such as headache, cognitive deficits, or focal weakness, rather than seizures; while the low-grade tumors, or large tumors were more likely to present with seizures than small tumors. Importantly, tumors located in the insular cortex are likely to be clinically silent until the patient experiences a seizure. A retrospective study showed 50 out of 51 insular grade II gliomas patients presented with seizures and 45 of them had a normal neurological examination [165]. Insular cortex is often a region of seizure spread in temporal lobe epilepsy. Clinically, seizures originating from the insular region are difficult to distinguish from those arising from temporal lobe [166] and $10 \%$ of patients initially thought to have temporal lobe epilepsy may in fact have seizures originating in the insular cortex [167]. High frequency of preoperative seizures has been reported in other smaller series describing low-grade insular tumors [148,168-171]. Interestingly, if a seizure occurs, high-grade tumors presenting with seizures are likely to be smaller than those presenting with other symptoms [164]. Notably, the left hemisphere tumors are less likely to present with seizures, perhaps because of increased presentation with other neurological findings as a result of greater eloquence of the dominant hemisphere [164]. Advanced imaging techniques allow early detection of the lesions and characterization of their propensities to cause seizures at presentation $[172,173]$.

Prophylactic anticonvulsant therapy has been proven to be ineffective in preventing seizures in patients with brain tumors in multiple large-scale studies $[158,174-176]$, and it is not recommended by the American Academy of Neurology [150]. Nonetheless, prophylaxis remains a widespread practice because of difficulty in determining which patients are at greatest risk for seizures.

\section{Obstructive sleep apnea}

Obstructive sleep apnea (OSA) is a common sleep disorder characterized by repeated episodes of complete or partially blockage of the upper airway during sleep. OSA is widely underdiagnosed [177] and is associated with significant morbidity and mortality due to intermittent anatomical blockage of the upper airway and consequential reduction or cessation of airflow. OSA is associated with many medical conditions including neurocognitive dysfunction [178], irritability, lack of energy and depression. Untreated OSA worsens seizure control [179] and is associated with a variety of potentially lifethreatening conditions including cardiac arrhythmias, hypertension, stroke, and myocardial infarction. OSA affects up to $24 \%$ of men and $9 \%$ of women [180] and is even more common in epilepsy, affecting more than $30 \%$ of patients with intractable seizures [181]. OSA has been documented in obesity and increases in incidence and prevalence with aging [181-186], males [181,182,184,187], hypertension $[186,188,189]$, and type 2 diabetes mellitus [190-194] with Epworth Sleepiness Scale (ESS) score of 10 or greater [195] and sleepiers $[181,184]$. Individuals with OSA may rarely be aware of having difficulty breathing, even upon awakening but may have daytime sleepiness, insomnia, morning headaches, fatigue, forgetfulness, difficulty concentrating, mood changes such as irritability, anxiety, and depression. Common symptoms suggestive of OSA include snoring, restless sleep, daytime fatigue and sleepiness [196]. Common signs of OSA include unexplained daytime sleepiness, restless sleep, and loud snoring. Less common symptoms are palpitation, increase in hypertension, decreased sex drive, unexplained weight gain, increased nocturia; gastroesophageal reflux disease; and heavy night sweats. The hypoxia caused by OSA may cause structural and functional alteration 
of neurons in the central nervous system (CNS). Neuro-imaging revealed evidence of hippocampal atrophy in OSA.

On the other hand, epilepsy worsens OSA. Studies have shown that patients with epilepsy are at higher risk for apnea than the general population (10.2\% vs. $4 \%$ ) [184], due to sedentary lifestyle or the adverse effects of antiepileptic drugs (AED) [181]. Clinical studies showed that $30 \%$ women and $73 \%$ men, who had epilepsy and aged 50 years and older, had an AHI of 5 or greater, suggesting OSA and epilepsy in older adults are comorbidities [179,183], particularly in obese individuals [197]. This comorbidity represents a diagnostic challenge because OSA can mimic seizures during sleep [198-200].

Sleep fragmentation in OSA can facilitate the occurrence of seizures and increase drowsiness in epilepsy patients [201], whereas epileptic seizures can induce apneas [202]. The coexistence of epilepsy and OSA may reciprocally aggravate the clinical course of each condition. Primarily, incidence of both OSA and epilepsy increases with age. The presence of OSA has been found higher in patients with refractory epilepsy [181,184,203-207] but lower in general populations $[184,205,208-210]$. Patients with epilepsy have been shown to be more likely to have OSA because of nocturnal seizures, use of CNS suppressing medications, and sedentary lifestyle. The appearance of OSA symptoms coincided with a clear increase in seizure frequency or the first appearance of status epileptics [211]. OSA leads to increased disturbances of cardiac, respiratory, and metabolic conditions, including hypertension, stroke and congestive heart failure, all are potential risks for seizures [212]. Older adults with new onset seizures or worsening epilepsy were more likely to have OSA than similarlyaged patients without OSA [179]. Multiple case series have shown its coexistence with epilepsy $[179,184,201,204,213-215]$. Treatment of OSA reduces seizure frequency and improves seizure control in medically refractory cases [196,201,204,209,213,214,216,217]. Finally, epilepsy surgery candidates who had OSA were more likely to have nocturnal seizures than those without OSA [181] and OSA surgery reduces seizure frequencies in children [218].

Several mechanisms may contribute to the increased incidence of OSA in patients with epilepsy. The adverse effects of AEDs on CNS; decrease in arousal threshold and upper airway muscle tone, weight gain; and reduced physical activity of patients with epilepsy; all can adversely affect OSA $[219,220]$. Barbiturates and benzodiazepines may precipitate or exacerbate OSA [221,222]. Weight gain, which is most notably seen with valproic acid and carbamazepine in both children [223] and adults [222,224], may lead to clinically significant OSA in predisposed individuals. A prospectively randomized clinical trial in nearly 700 adults when adjusting for gender, age and smoking habits demonstrated that weight changes proportionately correlated with the changes of AHI over time [225]. At the lower range of AHI, each 1\% change in weight was associated with a $3 \%$ difference in AHI, therefore, an increase in body weight of $10 \%$ resulted in an increase in AHI of 30\%. Individuals with epilepsy are usually less physically active than age-matched controls as demonstrated by significant differences in aerobic endurance, muscle strength endurance and flexibility, and greater body mass index (BMI) [226,227].

It is well known that sleep deprivation can activate epileptic activity as depicted during EEG or occasionally cause seizures in subjects without pre-existing epilepsy [228-234]. Notably, sleep deprivation facilitates interictal epileptiform discharges independent of the activating effects of sleep [235]. Sleep deprived mice become hyposensitve to diazepam, which may be due to alterations in the function of the GABA receptor [236]. Ironically, sleep deprivation has not been shown to increase seizure frequency during inpatient videoEEG monitoring [237], although questionnaire studies have shown a relationship between relative sleep deprivation and seizure frequency in temporal lobe epilepsy [238]. Polysomnogram (PSG) did not differ significantly between patients with or without OSA. But AHI in REM positively correlates to latency to slow wave sleep and the number of awaking showing that patients with epilepsy and OSA have significantly longer sleep latency and higher arousal index [239]. OSA tends to be worse in REM sleep whileas REM sleep induces skeletal muscle atonia, making the upper airways more susceptible to collapse [239].

Treatment of OSA improves seizure control in medically refractory cases [217] and reduces seizure frequency and severity in both adults [179,196,201,206,208,209,213,216,217,240-244] and children [209], possibly by consolidating sleep and reversing the effects of sleep deprivation. The effects of treatment of OSA in the patients with coexistence of OSA with epilepsy have been evidenced $[201,204,209,213,216,241,245]$. CPAP therapy may particularly benefit those OSA patients with generalized epilepsy, because of the influence of sleep and arousal on thalamocortical networks [246], and those with seizures that occur predominantly or exclusively during sleep, because of the influence of sleep stage transitions in facilitating seizures [181]. CPAP treatment in adult epilepsy significantly reduces the frequency of interictal spikes on EEG-PSG studies [247] and the improvement in seizure control particularly in obese patients [248]. Treating OSA may also allow for better tolerability of AEDs in patients with daytime sleepiness which is a major adverse effect of AEDs [245]. Improvement in seizure control, daytime sleepiness, or both has been demonstrated when OSA is effectively treated. Notably, a case report claimed OSA surgery was able to reduce seizure frequency in children [218]. Interestingly, moderate severity of OSA had been improved after a successful resection of left premotor frontal lobe in a young man with intractable focal epilepsy [249]. Improvement of epileptic seizures has been documented in effective treatment of OSA [201,206,208,213,216,217,241] by showing a reduction of interictal spikes on EEG [247] and $40-57 \%$ of patients with improvement in seizure frequencies independent of their AED changes. Epilepsy patients with OSA who used CPAP and were compliant with its use over a minimum period of 6 months had a better seizure control than those who were noncompliant with its use. Non-CPAP compliant patients had a $>1.5$-fold increased risk for ongoing seizures as compared to CPAP-compliant patients, suggesting that treatment of OSA may contribute to better seizure control and seizure freedom in patients with epilepsy [241]. Vendrame and colleagues showed 57\% (16/28) of CPAP compliant patients became seizure free compared to $10 \%(3 / 28)$ of noncompliant patients in a retrospective study [241]. Uncontrolled series and randomized pilot trials demonstrated the benefits of CPAP on seizure frequency in adults [196,201,209,213]. Interestingly, all the refractory epilepsy patients with OSA who were compliant with CPAP showed significant improvement in their seizure control [217], however, Malow and colleagues showed there was no significant difference in seizure reduction in severely refractory epilepsy patients after CPAP treatment compared with the sham CPAP group [196], suggesting that the hypoxic effects in severely refractory epilepsy population might have been too advanced to be reversed by CPAP therapy. Nonetheless, early and appropriate treatment of OSA may improve symptoms and quality of life in patients with epilepsy. 


\section{Obesity}

Obesity is a chronic medical condition. In the United States, over two-thirds of adults are overweight, and one-third of the adult population suffers from obesity [250]. There is a higher prevalence in certain ethnic populations, including African-, Asian-, and MexicanAmericans [251,252]. There are two most common measures in classifying obesity: BMI and waist-to-hip ratio. BMI is a ratio of body weight in kilograms divided by height in meters squared which is widely used for estimating body fat for most adults between 19 to 70 years of age, and correlates well with total body fat content in adults. An adult who has a BMI of 25-29.9 is considered overweight and over 30 obese. BMI of 35-40 is classified as severe obesity, 40-44.9 morbid obesity, and BMI greater than 45 is super obesity [251,253]. The waistto-hip ratio (in inches) is obtained by measuring the waist at its narrowest point and the hips at the widest point, in order to estimate where the fat is deposited. The pattern of body fat distribution differs in men and women. Women usually deposit fat in their hips and buttocks, displaying a "pear" shape, while men deposit fat in abdomen, making an "apple" appearance. Waist-to-hip ratios of greater than 0.8 in women and more than 1.0 in men are "apples". Apple-shaped individuals are more likely to suffer from medical problems related to obesity [253]. Obese patients, especially those with a central distribution of fat, or "apples", have an increased risk of various medical disorders such as cardiovascular disease, stroke, and diabetes $[251,253]$.

Obesity may be linked with a plethora of medical conditions such as degenerative osteoarthritis, diabetes mellitus, hypertension, cardiac disease, OSA, depression, dementia, stroke, headache, neuropathies, multiple sclerosis, and certain types of cancer [253]. In epilepsy, body weight gain is a common adverse effect from some AEDs, particularly valproic acid and carbamazepine, however, whether there is correlation between the obesity and increased risk of seizures in seniors remains to be elucidated.

\section{Seizure mimics in elderly}

Several types of transient episodes mimic seizures. Syncope can be confused with a seizure because of the presentation of a sudden fall with transient loss of consciousness and muscle twitches or myoclonus, tongue biting and urinary incontinence. The etiologies for syncopies are mainly cardiovasculogenic. Transient global amnesia (TGA) can also be confused with a seizure event, particularly epileptic amnesic syndrome (EAS) or transient epileptic amnesia (TEA) [254], which is a type of temporal lobe epilepsies $[255,256]$. TGA is a welldescribed syndrome for more than 50 years with a characteristic of a temporary but almost complete inability to retrieve short-term memory with a range of problems accessing older memories. A person in a state of TGA exhibits no other signs of impaired cognitive functioning but recalls only the last few moments of consciousness, such as his or her own name [257,258]. TGA is usually seen in a middle aged or older person presented with an abrupt onset of severe anterograde amnesia, usually accompanied by repetitive questioning. During the attack the patients remained alert and communicative, no clouding of consciousness or loss of personal identity, absence of neurological signs or deficits, no features suggesting epilepsy or active epilepsy, no recent head injury, and resolution within 24 hours [258-264]. TGA is sometimes difficult to differentiate from EAS or TEA. Like TGA, EAS or TEA usually occurs in the elderly in good health without any history of cognitive disturbances. It consists of repetitive and transient memory impairment, which lasts a few minutes. It may be the sole manifestation of a seizure or following a seizure. Amnesia in EAS or TEA is anterograde, retrograde or both and is sometimes associated with a few behavioral abnormalities (e.g. perplexity), with no memory of the episodes [254]. EEG may be normal or show nonspecific or paroxysmal abnormalities prevalent in the temporal regions especially recorded during sleep or after sleep deprivation. Brain CT or MRI scans are normal or show nonspecific moderate atrophy, generally prevalent in cortical and particularly temporal regions [254]. The duration, usually 4-6 hours in TGA but usually less than 1 hour in EAS or TEA; the number of attacks, repetitive episodes in EAS or TEA may help to distinguish TGA from EAS or TEA. It was argued whether TGA is clinically reminiscent of transient epileptic amnesia, which may have an epileptic or ischemic origin. Independent mesial temporal lobe spike discharges also have been described in TGA which may be due to transient ischemic attack [265-272]. Amnesia in epileptic patients has usually been considered an ictal or postictal manifestation [273]. EAS or TEA is a treatable unrecognized cause of episodic amnestic wandering and disorientation, which can be seen in $\mathrm{AD}$ and demented patients with epileptiform activity [140,274]. Empiric treatment with AEDs reduces episodic behavioral changes of transient amnestic wandering spells caused by ictal or postictal epileptic events [254,255,269,274,275].

Many patients with $\mathrm{AD}$ experience fluctuations in cognitive functions such as transient episodes of amnestic wandering and disorientation [144,276]. Epilepsy itself has a significantly adverse impact on the quality of life in patients with seizures. Seizures can worsen cognitive performance, particularly in language, decrease autonomy, and increase risk of injury and mortality rate. In elderly with dementia, seizure activities, particularly complex partial seizures, may be manifested as a decline in cognitive functions and worsening in the performance of activities of daily living with episodes of confusion [274]. It can be mistakenly considered as a symptom of the underlying dementia. Old adults with epilepsy can also present with non-specific symptoms like dizziness, altered mental status, or unresponsiveness, however, there are no reliable markers, particularly in elderly seizures with neurodegenerative disorders [277]. The intermittent inability to retrieve memories cannot be easily explained by relatively protracted processes such as neuronal loss, plaque deposition, or tangle formation. It seems more likely due to abnormal neuronal network activity. Epileptiform EEG discharges such as spikes and sharp waves have been documented in $\mathrm{AD}$ patients with amnestic episodes [274] and these specific cognitive disturbances and the associated epileptiform EEG discharges can be eradicated by administration of AEDs [274]. On the other hand, epileptiform discharges in temporal lobe epilepsy patients may cause memory disturbances simulating AD-like clinical phenotype [278].

\section{Treatment of seizures in elderly}

Management of seizures in seniors must be individualized because of the varieties of their seizure types and comorbidities $[279,280]$. The pathophysiologic conditions in seniors are generally compromised when compared to young adults.

Although treatment for epilepsy may stop seizures or decrease the severity and frequencies of epilepsy and have beneficial effects on cognitive performance, adverse effects of AEDs can cause untoward cognitive and behavioral effects [281-283]. Indeed, AEDs are a common cause of such morbidity [284,285]. Epilepsy surgical intervention may partially reverse or prevent cognitive deterioration, but left-temporal resections have a high risk of postoperative verbal 
memory impairment [286], however, cognitive disturbance after epilepsy surgery in most cases can be minimized or avoided [287,288].

\section{Conclusion}

Epilepsy is a frequently seen and significantly increased in elderly. The diagnosis of a seizure is a clinical challenge, particularly in demented patients since they often remember little of the episodes. The diagnosis of a seizure is essentially a clinical exercise based on a reliable history, most often based on questions to the caregiver. Corroborative evidence from the caregiver or an observer is important. The most common cause of provoked seizures in elderly is acute stroke. Elderly are at increased risk for TBI, which is an important factor to cause seizure and epilepsy because of their pathophysiologic conditions and inclination to falls. Brain tumors are a recognized risk factor for epilepsy in elderly. Frequently associated with seizures are low grade well-differentiated tumors, cortical location, particularly in the temporal, frontal and motor or sensory cortices. The most common types of brain tumors in elderly are gliomas, meningiomas and metastases. Episodes of chronic seizure itself and the result of psychosocial disruption of patients' lifestyles significantly impair patients' quality of life. Poor cognitive outcome is generally associated with an early onset and a long duration of the epilepsy, with poor seizure control. Epilepsy in dementia has significant consequences on the prognosis of the underlying dementia. Additionally, old adults with a seizure are vulnerable to the adverse effects of medications. OSA affects one third epilepsies and is associated with a variety of medical comorbidities. OSA is particularly prevalent seen in elderly, male and in those who have seizures during sleep. Treatment with CPAP significantly reduces the frequency of interictal spikes on EEG-PSG studies, enhances seizure control, and improves quality of life in patients with OSA and epilepsy.

\section{References}

1. Farlex: Dictionary (2013) : The Free dictionary, Internet, pp Definition.

2. Wiki: Senior citizen (2013): Free Encyclopedia, WikiPedia.

3. Forum (2012) : Older americans, key indicators of well-being. Federal interagency forum on aging-related statistics (forum).

4. Meador KJ (2002) Cognitive outcomes and predictive factors in epilepsy. Neurology 58: S21-26.

5. Smith DB, Craft BR, Collins J, Mattson RH, Cramer JA (1986) Behavioral characteristics of epilepsy patients compared with normal controls. Epilepsia 27: 760-768.

6. Jokeit H, Ebner A (2002) Effects of chronic epilepsy on intellectual functions. Prog Brain Res 135: 455-463.

7. Forsgren L, Bucht G, Eriksson S, Bergmark L (1996) Incidence and clinical characterization of unprovoked seizures in adults: a prospective population-based study. Epilepsia 37: 224-229.

8. Keränen T, Sillanpää M, Riekkinen PJ (1988) Distribution of seizure types in an epileptic population. Epilepsia 29: 1-7.

9. Fisher RS, Webber WR, Lesser RP, Arroyo S, Uematsu S (1992) Highfrequency EEG activity at the start of seizures. J Clin Neurophysiol 9: 441-448.

10. Hauser WA (1992) Seizure disorders: the changes with age. Epilepsia 33 Suppl 4: S6-14.

11. Hauser WA (1992) The natural history of drug resistant epilepsy: epidemiologic considerations. Epilepsy Res Suppl 5: 25-28.

12. Thomas P, Beaumanoir A, Genton P, Dolisi C, Chatel M (1992) 'De novo' absence status of late onset: report of 11 cases. Neurology 42: 104-110.

13. Frey LC (2003) Epidemiology of posttraumatic epilepsy: a critical review. Epilepsia 44 Suppl 10: 11-17.
14. (1993) Guidelines for epidemiologic studies on epilepsy. Commission on Epidemiology and Prognosis, International League Against Epilepsy. Epilepsia 34: 592-596.

15. (1989) Proposal for revised classification of epilepsies and epileptic syndromes. Commission on classification and terminology of the international league against epilepsy. Epilepsia30:389-399.

16. Lowenstein DH, Alldredge BK (1998) Status epilepticus. N Engl J Med 338: 970-976.

17. (2012) WHO: Epilepsy fact sheet: WHO Media centre.

18. Stephen LJ, Brodie MJ (2000) Epilepsy in elderly people. Lancet 355: 1441-1446.

19. Faught E (1999) Epidemiology and drug treatment of epilepsy in elderly people. Drugs Aging 15: 255-269.

20. Luhdorf K, Jensen LK, Plesner AM (1986) Epilepsy in the elderly: Prognosis. Acta Neurol Scand 74: 409-415.

21. de la Court A, Breteler MM, Meinardi H, Hauser WA, Hofman A (1996) Prevalence of epilepsy in the elderly: the Rotterdam Study. Epilepsia 37: 141-147.

22. Hauser WA, Annegers JF, Kurland LT (1993) Incidence of epilepsy and unprovoked seizures in Rochester, Minnesota: 1935-1984. Epilepsia 34: 453-468.

23. Hauser WA, Annegers JF, Rocca WA (1996) Descriptive epidemiology of epilepsy: contributions of population-based studies from Rochester, Minnesota. Mayo Clin Proc 71: 576-586.

24. Granger N, Convers P, Beauchet O, Imler D, Viallon A (2002) First epileptic seizure in the elderly: electroclinical and etiological data in 341 patients. Rev Neurol (Paris) 158: 1088-1095.

25. Hesdorffer DC, Hauser WA, Annegers JF, Kokmen E, Rocca WA (1996) Dementia and adult-onset unprovoked seizures. Neurology 46: 727-730.

26. Jallon P, Loiseau P, Loiseau J (2001): Newly diagnosed unprovoked epileptic seizures: Presentation at diagnosis in carole study. Coordination active du reseau observatoire longitudinal de l' epilepsie. Epilepsia 42: 464-475.

27. Loiseau J, Loiseau P, Duché B, Guyot M, Dartigues JF (1990) A survey of epileptic disorders in southwest France: seizures in elderly patients. Ann Neurol 27: 232-237.

28. Rodriguez D (2009) : Epilepsy and older adults; in Bass PF

29. Annegers JF, Hauser WA, Lee JR, Rocca WA (1995) Incidence of acute symptomatic seizures in Rochester, Minnesota, 1935-1984. Epilepsia 36: 327-333.

30. Tallis R, Hall G, Craig I, Dean A (1991) How common are epileptic seizures in old age? Age Ageing 20: 442-448.

31. Wallace H, Shorvon S, Tallis R (1998) Age-specific incidence and prevalence rates of treated epilepsy in an unselected population of $2,052,922$ and age-specific fertility rates of women with epilepsy. Lancet 352: 1970-1973.

32. Cloyd J, Hauser W, Towne A, Ramsay R, Mattson R (2006) Epidemiological and medical aspects of epilepsy in the elderly. Epilepsy Res 68 Suppl 1: S39-48.

33. Sidenvall R, Forsgren L, Blomquist HK, Heijbel J (1993) A communitybased prospective incidence study of epileptic seizures in children. Acta Paediatr 82: 60-65.

34. Olafsson E, Ludvigsson P, Gudmundsson G, Hesdorffer D, Kjartansson O (2005) Incidence of unprovoked seizures and epilepsy in Iceland and assessment of the epilepsy syndrome classification: a prospective study. Lancet Neurol 4: 627-634.

35. Mendez M, Lim G (2003) Seizures in elderly patients with dementia: epidemiology and management. Drugs Aging 20: 791-803.

36. Pugh MJ, Knoefel JE, Mortensen EM, Amuan ME, Berlowitz DR (2009) New-onset epilepsy risk factors in older veterans. J Am Geriatr Soc 57: 237-242.

37. Beghi M, Savica R, Beghi E, Nobili A, Garattini L (2009) Utilization and costs of antiepileptic drugs in the elderly: still an unsolved issue. Drugs Aging 26: 157-168. 
38. Johnston A, Smith PE (2010) Epilepsy in the elderly. Expert Rev Neurother 10: 1899-1910.

39. Holden EW, Thanh Nguyen H, Grossman E, Robinson S, Nelson LS (2005) Estimating prevalence, incidence, and disease-related mortality for patients with epilepsy in managed care organizations. Epilepsia 46: 311-319.

40. Parko K, Thurman DJ (2009) Prevalence of epilepsy and seizures in the Navajo Nation 1998-2002. Epilepsia 50: 2180-2185.

41. Schachter SC, Cramer GW, Thompson GD, Chaponis RJ, Mendelson MA (1998) An evaluation of antiepileptic drug therapy in nursing facilities. J Am Geriatr Soc 46: 1137-1141.

42. Hussain SA, Haut SR, Lipton RB, Derby C, Markowitz SY (2006) Incidence of epilepsy in a racially diverse, community-dwelling, elderly cohort: results from the Einstein aging study. Epilepsy Res 71: 195-205.

43. Faught E, Richman J, Martin R, Funkhouser E, Foushee R (2012) Incidence and prevalence of epilepsy among older U.S. Medicare beneficiaries. Neurology 78: 448-453.

44. Haerer AF, Anderson DW, Schoenberg BS (1986) Prevalence and clinical features of epilepsy in a biracial United States population. Epilepsia 27: 66-75.

45. Lühdorf K, Jensen LK, Plesner AM (1986) Epilepsy in the elderly: incidence, social function, and disability. Epilepsia 27: 135-141.

46. Lloyd-Jones D, Adams RJ, Brown TM, Carnethon M, Dai S et al. (2010) : Heart disease and stroke statistics--2010 update: A report from the american heart association. Circulation 121: 46-215.

47. Gilmore PC, Brenner RP (1981) Correlation of EEG, computerized tomography, and clinical findings. Study of 100 patients with focal delta activity. Arch Neurol 38: 371-372.

48. Lühdorf K, Jensen LK, Plesner AM (1986) Etiology of seizures in the elderly. Epilepsia 27: 458-463.

49. Fang MC (2011) Anticoagulation in people with atrial fibrillation. BMJ 342: d530.

50. Cleary P, Shorvon S, Tallis R (2004) Late-onset seizures as a predictor of subsequent stroke. Lancet 363: 1184-1186.

51. Mohr JP, Caplan LR, Melski JW, Goldstein RJ, Duncan GW (1978) The Harvard Cooperative Stroke Registry: a prospective registry. Neurology 28: 754-762.

52. Meyer JS, Charney JZ, Rivera VM, Mathew NT (1971) Cerebra embolization: prospective clinical analysis of 42 cases. Stroke 2: 541-554.

53. Lossius MI, Rønning OM, Mowinckel P, Gjerstad L (2002) Incidence and predictors for post-stroke epilepsy. A prospective controlled trial. The Akershus stroke study. Eur J Neurol 9: 365-368.

54. Lossius MI, Rønning OM, Slapø GD, Mowinckel P, Gjerstad L (2005) Poststroke epilepsy: occurrence and predictors--a long-term prospective controlled study (Akershus Stroke Study). Epilepsia 46: 1246-1251.

55. Bladin CF, Alexandrov AV, Bellavance A, Bornstein N, Chambers B (2000) Seizures after stroke: a prospective multicenter study. Arch Neurol 57: 1617-1622.

56. Arboix A, García-Eroles L, Massons JB, Oliveres M, Comes E (1997) Predictive factors of early seizures after acute cerebrovascular disease. Stroke 28: 1590-1594

57. Reith J, Jørgensen HS, Nakayama H, Raaschou HO, Olsen TS (1997) Seizures in acute stroke: predictors and prognostic significance. The Copenhagen Stroke Study. Stroke 28: 1585-1589.

58. Giroud M, Gras P, Fayolle H, André N, Soichot P (1994) Early seizures after acute stroke: a study of 1,640 cases. Epilepsia 35: 959-964.

59. Burn J, Dennis M, Bamford J, Sandercock P, Wade D (1997) Epileptic seizures after a first stroke: the Oxfordshire Community Stroke Project. BMJ 315: 1582-1587.

60. Lancman ME, Golimstok A, Norscini J, Granillo R (1993) Risk factors for developing seizures after a stroke. Epilepsia 34: 141-143.

61. Lesser RP, Lüders H, Dinner DS, Morris HH (1985) Epileptic seizures due to thrombotic and embolic cerebrovascular disease in older patients. Epilepsia 26: 622-630
62. Hornig CR, Buttner T, Hufnagel A, Schroder-Rosenstock K, Dorndorf W (1990) Epileptic seizures following ischaemic cerebral infarction. Clinical picture, ct findings and prognosis. Eur Arch Psychiatry Neurol Sci 239: 379-383.

63. Sung CY, Chu NS (1989) Epileptic seizures in intracerebral haemorrhage. J Neurol Neurosurg Psychiatry 52: 1273-1276.

64. Dhanuka AK, Misra UK, Kalita J (2001) Seizures after stroke : a prospective clinical study. Neurol India 49: 33-36.

65. Horner S, Ni XS, Duft M, Niederkorn K, Lechner H (1995) EEG, CT and neurosonographic findings in patients with postischemic seizures. J Neurol Sci 132: 57-60

66. So EL, Annegers JF, Hauser WA, O'Brien PC, Whisnant JP (1996) Population-based study of seizure disorders after cerebral infarction. Neurology 46: 350-355.

67. Vespa PM, O'Phelan K, Shah M, Mirabelli J, Starkman S, et al. (2003) Acute seizures after intracerebral hemorrhage: a factor in progressive midline shift and outcome. Neurology 60: 1441-1446.

68. Roberts MA, Godfrey JW, Caird FI (1982) Epileptic seizures in the elderly: I. Aetiology and type of seizure. Age Ageing 11: 24-28.

69. Sung CY, Chu NS (1990) Epileptic seizures in elderly people: aetiology and seizure type. Age Ageing 19: 25-30.

70. Brodie MJ, Kwan P (2005) Epilepsy in elderly people. BMJ 331: 1317-1322.

71. Ferguson PL, Smith GM, Wannamaker BB, Thurman DJ, Pickelsimer EE, et al. (2010) A population-based study of risk of epilepsy after hospitalization for traumatic brain injury. Epilepsia 51: 891-898.

72. Hiyoshi T, Yagi K (2000) Epilepsy in the elderly. Epilepsia 41 Suppl 9: 31-35.

73. Annegers JF, Coan SP (2000) The risks of epilepsy after traumatic brain injury. Seizure 9: 453-457.

74. Jennett B (1973) Trauma as a cause of epilepsy in childhood. Dev Med Child Neurol 15: 56-62.

75. Semah F, Picot MC, Adam C, Broglin D, Arzimanoglou A, et al. (1998) Is the underlying cause of epilepsy a major prognostic factor for recurrence? Neurology 51: 1256-1262.

76. Agrawal A, Timothy J, Pandit L, Manju M (2006) Post-traumatic epilepsy: an overview. Clin Neurol Neurosurg 108: 433-439.

77. Weiss GH, Feeney DM, Caveness WF, Dillon D, Kistler JP, et al. (1983) Prognostic factors for the occurrence of posttraumatic epilepsy. Arch Neurol 40: 7-10.

78. Haltiner AM, Temkin NR, Dikmen SS (1997) Risk of seizure recurrence after the first late posttraumatic seizure. Arch Phys Med Rehabil 78: 835-840.

79. Christensen J, Pedersen MG, Pedersen CB, Sidenius P, Olsen J, et al. (2009) Long-term risk of epilepsy after traumatic brain injury in children and young adults: a population-based cohort study. Lancet 373: 1105-1110.

80. Asikainen I, Kaste M, Sarna S (1999) Early and late posttraumatic seizures in traumatic brain injury rehabilitation patients: brain injury factors causing late seizures and influence of seizures on long-term outcome. Epilepsia 40: 584-589.

81. Englander J, Bushnik T, Duong TT, Cifu DX, Zafonte R, et al. (2003) Analyzing risk factors for late posttraumatic seizures: a prospective, multicenter investigation. Arch Phys Med Rehabil 84: 365-373.

82. Wang HC, Chang WN, Chang HW, Ho JT, Yang TM, et al. (2008) Factors predictive of outcome in posttraumatic seizures. J Trauma 64: 883-888.

83. Angeleri F, Majkowski J, Cacchiò G, Sobieszek A, D'Acunto S, et al. (1999) Posttraumatic epilepsy risk factors: one-year prospective study after head injury. Epilepsia 40: 1222-1230.

84. Ferguson PL, Chiprich J, Smith G, Dong B, Wannamaker BB, et al (2008) Prevalence of self-reported epilepsy, health care access, and health behaviors among adults in South Carolina. Epilepsy Behav 13: 529-534. 
85. Armstrong KK, Sahgal V, Bloch R, Armstrong KJ, Heinemann A (1990) Rehabilitation outcomes in patients with posttraumatic epilepsy. Arch Phys Med Rehabil 71: 156-160.

86. De Santis A, Sganzerla E, Spagnoli D, Bello L, Tiberio F (1992) Risk factors for late posttraumatic epilepsy. Acta Neurochir Suppl (Wien) 55: 64-67.

87. Salazar AM, Schwab K, Grafman JH (1995) Penetrating injuries in the Vietnam war. Traumatic unconsciousness, epilepsy, and psychosocial outcome. Neurosurg Clin N Am 6: 715-726.

88. De Reuck J (2011) Risk factors for late-onset seizures related to cerebral contusions in adults with a moderate traumatic brain injury. Clin Neurol Neurosurg 113: 469-471.

89. Chan KH, Tharakan J, Pal HK, Khan N, Tan YC (2010) Risk Factors and Phenytoin Prophylaxis for Early Post-Traumatic Seizures among Patients with Traumatic Brain Injury. Malays J Med Sci 17: 36-43.

90. Pitkänen A, Immonen RJ, Gröhn OH, Kharatishvili I (2009) From traumatic brain injury to posttraumatic epilepsy: what animal models tel us about the process and treatment options. Epilepsia 50 Suppl 2: 21-29.

91. Pagni CA, Zenga F (2005) Posttraumatic epilepsy with special emphasis on prophylaxis and prevention. Acta Neurochir Suppl 93: 27-34.

92. Grisar T, Bottin P, de Borchgrave d'Alténa V, Brichart C, Delcourt C, et al. (2005) Prophylaxis of the epilepsies: should anti-epileptic drugs be used for preventing seizures after acute brain injury? Acta Neurol Belg 105: 5-13.

93. Benardo LS (2003) Prevention of epilepsy after head trauma: do we need new drugs or a new approach? Epilepsia 44 Suppl 10: 27-33.

94. Temkin NR (2003) Risk factors for posttraumatic seizures in adults. Epilepsia 44 Suppl 10: 18-20.

95. Schierhout G, Roberts I (2000) Anti-epileptic drugs for preventing seizures following acute traumatic brain injury. Cochrane Database Syst Rev : CD000173.

96. Schierhout G, Roberts I (2001) Anti-epileptic drugs for preventing seizures following acute traumatic brain injury. Cochrane Database Syst Rev : CD000173.

97. [No authors listed] (2000) The Brain Trauma Foundation. The American Association of Neurological Surgeons. The Joint Section on Neurotrauma and Critical Care. Role of antiseizure prophylaxis following head injury. J Neurotrauma 17: 549-553.

98. Liu KC, Bhardwaj A (2007) Use of prophylactic anticonvulsants in neurologic critical care: a critical appraisal. Neurocrit Care 7: 175-184.

99. Teasell R, Bayona N, Lippert C, Villamere J, Hellings C (2007) Posttraumatic seizure disorder following acquired brain injury. Brain Inj 21: 201-214.

100. Bratton SL, Chestnut RM, Ghajar J, McConnell Hammond FF, Harris OA, et al. (2007) Guidelines for the management of severe traumatic brain injury. Xiii. Antiseizure prophylaxis. J Neurotrauma 24 Suppl 1: S83-86.

101. Ramaroson H, Helmer C, Barberger-Gateau P, Letenneur L, Dartigues JF; PAQUID (2003) [Prevalence of dementia and Alzheimer's disease among subjects aged 75 years or over: updated results of the PAQUID cohort]. Rev Neurol (Paris) 159: 405-411.

102. Helmer C, Pérès K, Letenneur L, Guttiérez-Robledo LM, Ramaroson H, et al. (2006) Dementia in subjects aged 75 years or over within the PAQUID cohort: prevalence and burden by severity. Dement Geriatr Cogn Disord 22: 87-94.

103. De Ronchi D, Berardi D, Menchetti M, Ferrari G, Serretti A, et al. (2005) Occurrence of cognitive impairment and dementia after the age of 60: a population-based study from Northern Italy. Dement Geriatr Cogn Disord 19: 97-105.

104. Anderson VE, Hauser WA, Rich SS (1986) Genetic heterogeneity in the epilepsies. Adv Neurol 44: 59-75.

105. Romanelli MF, Morris JC, Ashkin K, Coben LA (1990) Advanced Alzheimer's disease is a risk factor for late-onset seizures. Arch Neurol 47: 847-850.
106. Amatniek JC, Hauser WA, DelCastillo-Castaneda C, Jacobs DM, Marder $\mathrm{K}$, et al. (2006) Incidence and predictors of seizures in patients with Alzheimer's disease. Epilepsia 47: 867-872.

107. Scarmeas N, Honig LS, Choi H, Cantero J, Brandt J, et al. (2009) Seizures in Alzheimer disease: who, when, and how common? Arch Neurol 66: 992-997.

108. McAreavey MJ, Ballinger BR, Fenton GW (1992) Epileptic seizures in elderly patients with dementia. Epilepsia 33: 657-660.

109. Risse SC, Lampe TH, Bird TD, Nochlin D, Sumi SM, et al. (1990) Myoclonus, seizures, and paratonia in Alzheimer disease. Alzheimer Dis Assoc Disord 4: 217-225.

110. Förstl H, Burns A, Levy R, Cairns N, Luthert P, et al. (1992) Neurologic signs in Alzheimer's disease. Results of a prospective clinical and neuropathologic study. Arch Neurol 49: 1038-1042.

111. Armon C, Peterson GW, Liwnicz BH (2000) Alzheimer's disease underlies some cases of complex partial status epilepticus. J Clin Neurophysiol 17: 511-518.

112. Chandra V, Bharucha NE, Schoenberg BS (1986) Conditions associated with Alzheimer's disease at death: case-control study. Neurology 36: 209-211.

113. Volicer L, Smith S, Volicer BJ (1995) Effect of seizures on progression of dementia of the Alzheimer type. Dementia 6: 258-263.

114. Griffith HR, Martin RC, Bambara JK, Marson DC, Faught E (2006) Older adults with epilepsy demonstrate cognitive impairments compared with patients with amnestic mild cognitive impairment. Epilepsy Behav 8: 161-168.

115. Griffith HR, Netson KL, Harrell LE, Zamrini EY, Brockington JC, et al. (2006) Amnestic mild cognitive impairment: diagnostic outcomes and clinical prediction over a two-year time period. J Int Neuropsychol Soc 12: 166-175.

116. Kwan P, Brodie MJ (2001) Neuropsychological effects of epilepsy and antiepileptic drugs. Lancet 357: 216-222.

117. Lobo A, Launer LJ, Fratiglioni L, Andersen K, Di Carlo A et al. (2000) Prevalence of dementia and major subtypes in europe: A collaborative study of population-based cohorts. Neurologic diseases in the elderly research group. Neurology 54: S4-9.

118. Hommet C, Mondon K, Camus V, De Toffol B, Constans T (2008) Epilepsy and dementia in the elderly. Dement Geriatr Cogn Disord 25: 293-300.

119. Kamenetz F, Tomita T, Hsieh H, Seabrook G, Borchelt D, et al. (2003) App processing and synaptic function. Neuron37: 925-937.

120. Hsieh H, Boehm J, Sato C, Iwatsubo T, Tomita T, et al. (2006) AMPAR removal underlies Abeta-induced synaptic depression and dendritic spine loss. Neuron 52: 831-843.

121. Takao M, Ghetti B, Murrell JR, Unverzagt FW, Giaccone G, et al. (2001) Ectopic white matter neurons, a developmental abnormality that may be caused by the PSEN1 S169L mutation in a case of familial AD with myoclonus and seizures. J Neuropathol Exp Neurol 60: 1137-1152.

122. Velez-Pardo C, Arellano JI, Cardona-Gomez P, Jimenez Del Rio M, Lopera F, et al. (2004) CA1 hippocampal neuronal loss in familial Alzheimer's disease presenilin-1 E280A mutation is related to epilepsy. Epilepsia 45: 751-756.

123. Ezquerra M, Carnero C, Blesa R, Gelpí JL, Ballesta F, et al. (1999) A presenilin 1 mutation (Ser169Pro) associated with early-onset AD and myoclonic seizures. Neurology 52: 566-570.

124. Shrimpton AE, Schelper RL, Linke RP, Hardy J, Crook R, et al (2007) A presenilin 1 mutation (1420r) in a family with early onset alzheimer disease, seizures and cotton wool plaques, but not spastic paraparesis. Neuropathology 27: 228-232.

125. Mendez MF, Catanzaro P, Doss RC, ARguello R, Frey WH 2nd (1994) Seizures in Alzheimer's disease: clinicopathologic study. J Geriatr Psychiatry Neurol 7: 230-233.

126. Hauser WA, Morris ML, Heston LL, Anderson VE (1986) Seizures and myoclonus in patients with Alzheimer's disease. Neurology 36: 1226-1230. 
127. Ramsay RE, Pryor F (2000) Epilepsy in the elderly. Neurology 55: S9-14.

128. Smits LL, Liedorp M, Koene T, Roos-Reuling IE, Lemstra AW, et al. (2011) EEG abnormalities are associated with different cognitive profiles in Alzheimer's disease. Dement Geriatr Cogn Disord 31: 1-6.

129. Liedorp M, Stam CJ, van der Flier WM, Pijnenburg YA, Scheltens P (2010) Prevalence and clinical significance of epileptiform EEG discharges in a large memory clinic cohort. Dement Geriatr Cogn Disord 29: 432-437.

130. Katherman AE, Knecht CD, Redding RW (1985) Effects of fentanyl citrate and droperidol on electroencephalographic findings in dogs. Am J Vet Res 46: 974-976.

131. Banoczi W (2005) How some drugs affect the electroencephalogram (EEG). Am J Electroneurodiagnostic Technol 45: 118-129.

132. Daly I, Billinger M, Scherer R, Muller-Putz G (2013) On the automated removal of artifacts related to head movement from the EEG. IEEE Trans Neural Syst Rehabil Eng 21: 427-434.

133. Khlif MS, Colditz PB, Boashash B (2013) Effective implementation of time-frequency matched filter with adapted pre and postprocessing for data-dependent detection of newborn seizures. Med Eng Phys 35: 1762-1769.

134. Alschuler DM, Tenke CE, Bruder GE, Kayser J (2014) Identifying electrode bridging from electrical distance distributions: A survey of publicly-available EEG data using a new method. Clin Neurophysiol 125: 484-490.

135. OBRIST WD (1954) The electroencephalogram of normal aged adults. Electroencephalogr Clin Neurophysiol 6: 235-244.

136. SILVERMAN AJ, BUSSE EW, BARNES RH (1955) Studies in the processes of aging: electroencephalographic findings in 400 elderly subjects. Electroencephalogr Clin Neurophysiol 7: 67-74.

137. Ala TA, Beh GO, Frey WH 2nd (2000) Pure hippocampal sclerosis: a rare cause of dementia mimicking Alzheimer's disease. Neurology 54: 843-848.

138. Puschmann A, Ross OA, Vilarino-Guell C, Lincoln SJ, Kachergus JM, et al. (2009) A swedish family with de novo alpha-synuclein a53t mutation: Evidence for early cortical dysfunction. Parkinsonism Relat Disord 15: 627-632.

139. Puschmann A, Wszolek ZK, Farrer M, Gustafson L, Widner H, et al. (2009) Alpha-synuclein multiplications with parkinsonism, dementia or progressive myoclonus? Parkinsonism Relat Disord 15: 390-392.

140. Palop JJ, Mucke L (2009) Epilepsy and cognitive impairments in Alzheimer disease. Arch Neurol 66: 435-440.

141. Palop JJ, Mucke L (2010) Synaptic depression and aberrant excitatory network activity in Alzheimer's disease: two faces of the same coin? Neuromolecular Med 12: 48-55.

142. Mikolaenko I, Mikolaenko I, Conner MG, Jinnah HA (2006) A 50-yearold man with acute-onset generalized seizure. Cerebral amyloid angiopathy and associated giant cell reaction. Arch Pathol Lab Med 130: e5-7.

143. Palop JJ, Chin J, Roberson ED, Wang J, Thwin MT, et al. (2007) Aberrant excitatory neuronal activity and compensatory remodeling of inhibitory hippocampal circuits in mouse models of Alzheimer's disease. Neuron 55: 697-711.

144. Palop JJ, Chin J, Mucke L (2006) A network dysfunction perspective on neurodegenerative diseases. Nature 443: 768-773.

145. Sander JW, Hart YM, Johnson AL, Shorvon SD (1990) National General Practice Study of Epilepsy: newly diagnosed epileptic seizures in a general population. Lancet 336: 1267-1271.

146. Forsgren L (1990) Prospective incidence study and clinical characterization of seizures in newly referred adults. Epilepsia 31: 292-301.

147. Austin J, Abdulla A (2013) Identifying and managing epilepsy in older adults. Nurs Times 109: 20-23.

148. Chang EF, Potts MB, Keles GE, Lamborn KR, Chang SM, et al. (2008) Seizure characteristics and control following resection in 332 patients with low-grade gliomas. J Neurosurg 108: 227-235.
149. van Breemen MS, Wilms EB, Vecht CJ (2007) Epilepsy in patients with brain tumours: epidemiology, mechanisms, and management. Lancet Neurol 6: 421-430.

150. Glantz MJ, Cole BF, Forsyth PA, Recht LD, Wen PY, Chamberlain MC, Grossman SA, Cairncross JG: Practice parameter: Anticonvulsant prophylaxis in patients with newly diagnosed brain tumors. Report of the quality standards subcommittee of the american academy of neurology. Neurology 2000;54:1886-1893.

151. Liigant A, Haldre S, Oun A, Linnamägi U, Saar A, et al. (2001) Seizure disorders in patients with brain tumors. Eur Neurol 45: 46-51.

152. Hildebrand J, Lecaille C, Perennes J, Delattre JY (2005) Epileptic seizures during follow-up of patients treated for primary brain tumors. Neurology 65: 212-215.

153. Vertosick FT Jr, Selker RG, Arena VC (1991) Survival of patients with well-differentiated astrocytomas diagnosed in the era of computed tomography. Neurosurgery 28: 496-501.

154. Lynam LM, Lyons MK, Drazkowski JF, Sirven JI, Noe KH, et al. (2007) Frequency of seizures in patients with newly diagnosed brain tumors: a retrospective review. Clin Neurol Neurosurg 109: 634-638.

155. Lote K, Stenwig AE, Skullerud K, Hirschberg H (1998) Prevalence and prognostic significance of epilepsy in patients with gliomas. Eur J Cancer 34: 98-102.

156. Fried I, Kim JH, Spencer DD (1994) Limbic and neocortical gliomas associated with intractable seizures: a distinct clinicopathological group. Neurosurgery 34: 815-823.

157. Bronen RA, Fulbright RK, Spencer DD, Spencer SS, Kim JH, et al. (1995) MR characteristics of neoplasms and vascular malformations associated with epilepsy. Magn Reson Imaging 13: 1153-1162.

158. Glantz MJ, Cole BF, Friedberg MH, Lathi E, Choy H, et al. (1996) A randomized, blinded, placebo-controlled trial of divalproex sodium prophylaxis in adults with newly diagnosed brain tumors. Neurology 46: 985-991.

159. Smith DF, Hutton JL, Sandemann D, Foy PM, Shaw MD, et al. (1991) The prognosis of primary intracerebral tumours presenting with epilepsy: the outcome of medical and surgical management. J Neurol Neurosurg Psychiatry 54: 915-920.

160. Zaatreh MM, Spencer DD, Thompson JL, Blumenfeld H, Novotny EJ, et al. (2002) Frontal lobe tumoral epilepsy: clinical, neurophysiologic features and predictors of surgical outcome. Epilepsia 43: 727-733.

161. Zaatreh MM, Firlik KS, Spencer DD, Spencer SS (2003) Temporal lobe tumoral epilepsy: characteristics and predictors of surgical outcome. Neurology 61: 636-641.

162. Chozick BS, Reinert SE, Greenblatt SH (1996) Incidence of seizures after surgery for supratentorial meningiomas: a modern analysis. J Neurosurg 84: $382-386$.

163. Lieu AS, Howng SL (2000) Intracranial meningiomas and epilepsy: incidence, prognosis and influencing factors. Epilepsy Res 38: 45-52.

164. Lee JW, Wen PY, Hurwitz S, Black P, Kesari S, et al. (2010) Morphological characteristics of brain tumors causing seizures. Arch Neurol 67: 336-342.

165. Duffau H (2009) A personal consecutive series of surgically treated 51 cases of insular WHO Grade II glioma: advances and limitations. J Neurosurg 110: 696-708.

166. PENFIELD W, FAULK ME Jr (1955) The insula; further observations on its function. Brain 78: 445-470.

167. Isnard J, Guénot M, Ostrowsky K, Sindou M, Mauguière F (2000) The role of the insular cortex in temporal lobe epilepsy. Ann Neurol 48: 614-623.

168. Moshel YA, Marcus JD, Parker EC, Kelly PJ (2008) Resection of insular gliomas: the importance of lenticulostriate artery position. J Neurosurg 109: 825-834.

169. Zentner J, Meyer B, Stangl A, Schramm J (1996) Intrinsic tumors of the insula: a prospective surgical study of 30 patients. J Neurosurg 85 : 263-271. 
170. Neuloh G, Pechstein U, Schramm J (2007) Motor tract monitoring during insular glioma surgery. J Neurosurg 106: 582-592.

171. Shankar A, Rajshekhar V (2003) Radiological and clinical outcome following stereotactic biopsy and radiotherapy for low-grade insular astrocytomas. Neurol India 51: 503-506.

172. Isnard J, Guénot M, Sindou M, Mauguière F (2004) Clinical manifestations of insular lobe seizures: a stereo-electroencephalographic study. Epilepsia 45: 1079-1090.

173. Rossetti AO, Mortati KA, Black PM, Bromfield EB (2005) Simple partial seizures with hemisensory phenomena and dysgeusia: an insular pattern. Epilepsia 46: 590-591.

174. Franceschetti S, Binelli S, Casazza M, Lodrini S, Panzica F, et al. (1990) Influence of surgery and antiepileptic drugs on seizures symptomatic of cerebral tumours. Acta Neurochir (Wien) 103: 47-51.

175. North JB, Penhall RK, Hanieh A, Frewin DB, Taylor WB (1983) Phenytoin and postoperative epilepsy. A double-blind study. J Neurosurg 58: 672-677.

176. Forsyth PA, Weaver S, Fulton D, Brasher PM, Sutherland G, et al. (2003) Prophylactic anticonvulsants in patients with brain tumour. Can J Neurol Sci 30: 106-112.

177. Décary A, Rouleau I, Montplaisir J (2000) Cognitive deficits associated with sleep apnea syndrome: a proposed neuropsychological test battery. Sleep 23: 369-381.

178. Naëgelé B, Thouvard V, Pépin JL, Lévy P, Bonnet C, et al. (1995) Deficits of cognitive executive functions in patients with sleep apnea syndrome. Sleep 18: 43-52.

179. Chihorek AM, Abou-Khalil B, Malow BA (2007) Obstructive sleep apnea is associated with seizure occurrence in older adults with epilepsy. Neurology 69: 1823-1827.

180. Young T, Palta M, Dempsey J, Skatrud J, Weber S et al. (1993) The occurrence of sleep-disordered breathing among middle-aged adults. $\mathrm{N}$ Engl J Med 328:1230-1235.

181. Malow BA, Levy K, Maturen K, Bowes R (2000) Obstructive sleep apnea is common in medically refractory epilepsy patients. Neurology 55: 1002-1007.

182. Young T, Shahar E, Nieto FJ, Redline S, Newman AB, et al. (2002) Predictors of sleep-disordered breathing in community-dwelling adults: the Sleep Heart Health Study. Arch Intern Med 162: 893-900.

183. Ancoli-Israel S, Kripke DF, Klauber MR, Mason WJ, Fell R, et al. (1991) Sleep-disordered breathing in community-dwelling elderly. Sleep 14: 486-495.

184. Manni R, Terzaghi M, Arbasino C, Sartori I, Galimberti CA, et al. (2003) Obstructive sleep apnea in a clinical series of adult epilepsy patients: frequency and features of the comorbidity. Epilepsia 44: 836-840.

185. Bixler EO, Vgontzas AN, Ten Have T, Tyson K, Kales A (1998) Effects of age on sleep apnea in men: I. Prevalence and severity. Am J Respir Crit Care Med 157: 144-148.

186. Gislason T, Aberg H, Taube A (1987) Snoring and systemic hypertension--an epidemiological study. Acta Med Scand 222: 415-421.

187. Leineweber C, Kecklund G, Akerstedt T, Janszky I, Orth-Gomér K (2003) Snoring and the metabolic syndrome in women. Sleep Med 4: 531-536.

188. Koskenvuo M, Kaprio J, Telakivi T, Partinen M, Heikkila K et al. (1987) Snoring as a risk factor for ischaemic heart disease and stroke in men. Br Med J (Clin Res Ed) 294:16-19.

189. Worsnop CJ, Naughton MT, Barter CE, Morgan TO, Anderson AI, et al. (1998) The prevalence of obstructive sleep apnea in hypertensives. Am J Respir Crit Care Med 157: 111-115.

190. Vgontzas AN, Papanicolaou DA, Bixler EO, Hopper K, Lotsikas A, et al. (2000) Sleep apnea and daytime sleepiness and fatigue: relation to visceral obesity, insulin resistance, and hypercytokinemia. J Clin Endocrinol Metab 85: 1151-1158.

191. Al-Delaimy WK, Manson JE, Willett WC, Stampfer MJ, Hu FB (2002) Snoring as a risk factor for type II diabetes mellitus: a prospective study. Am J Epidemiol 155: 387-393.
192. Al-Delaimy WK, Manson JE, Solomon CG, Kawachi I, Stampfer MJ, et al. (2002) Smoking and risk of coronary heart disease among women with type 2 diabetes mellitus. Arch Intern Med 162: 273-279.

193. West SD, Groves DC, Lipinski HJ, Nicoll DJ, Mason RH, et al. (2010) The prevalence of retinopathy in men with Type 2 diabetes and obstructive sleep apnoea. Diabet Med 27: 423-430.

194. West SD, Nicoll DJ, Stradling JR (2006) Prevalence of obstructive sleep apnoea in men with type 2 diabetes. Thorax 61: 945-950.

195. Al-Alawi A, Mulgrew A, Tench E, Ryan CF (2006) Prevalence, risk factors and impact on daytime sleepiness and hypertension of periodic leg movements with arousals in patients with obstructive sleep apnea. J Clin Sleep Med 2: 281-287.

196. Malow BA, Foldvary-Schaefer N, Vaughn BV, Selwa LM, Chervin RD, Weatherwax KJ, Wang L, Song Y: Treating obstructive sleep apnea in adults with epilepsy: A randomized pilot trial. Neurology 2008; 71:572-577.

197. Gross JB, Bachenberg KL, Benumof JL, Caplan RA, Connis RT et al. (2006) Practice guidelines for the perioperative management of patients with obstructive sleep apnea: A report by the american society of anesthesiologists task force on perioperative management of patients with obstructive sleep apnea. Anesthesiology 104:1081-1093; quiz 1117-1088.

198. Oldani A, Zucconi M, Castronovo C, Ferini-Strambi L (1998) Nocturnal frontal lobe epilepsy misdiagnosed as sleep apnea syndrome. Acta Neurol Scand 98: 67-71.

199. Oldani A, Ferini-Strambi L, Zucconi M (1998) Symptomatic nocturnal frontal lobe epilepsy. Seizure 7: 341-343.

200. Oldani A, Zucconi M, Asselta R, Modugno M, Bonati MT, et al. (1998) Autosomal dominant nocturnal frontal lobe epilepsy. A videopolysomnographic and genetic appraisal of 40 patients and delineation of the epileptic syndrome. Brain $121: 205-223$.

201. Devinsky O, Ehrenberg B, Barthlen GM, Abramson HS, Luciano D (1994) Epilepsy and sleep apnea syndrome. Neurology 44: 2060-2064.

202. So EL, Sam MC, Lagerlund TL (2000) Postictal central apnea as a cause of SUDEP: evidence from near-SUDEP incident. Epilepsia 41: 1494-1497.

203. Shaheen HA, Abd El-Kader AA, El Gohary AM, El-Fayoumy NM, Afifi LM (2012) Obstructive sleep apnea in epilepsy: a preliminary Egyptian study. Sleep Breath 16: 765-771.

204. Malow BA, Fromes GA, Aldrich MS (1997) Usefulness of polysomnography in epilepsy patients. Neurology 48: 1389-1394.

205. Weatherwax KJ, Lin X, Marzec ML, Malow BA (2003) Obstructive sleep apnea in epilepsy patients: The sleep apnea scale of the sleep disorders questionnaire (sa-sdq) is a useful screening instrument for obstructive sleep apnea in a disease-specific population. Sleep Med 4:517-521.

206. Beran RG, Plunkett MJ, Holland GJ (1999) Interface of epilepsy and sleep disorders. Seizure 8: 97-102.

207. Abd El Kader AA, Shaheen HA, El Gohary AM, Neveen M. El-Fayoumy NM, Afifi LM (2010) Clinical relevance of obstructive sleep apnea in epilepsy. Egypt J Neurol Psychiat Neurosurg 47:461-469.

208. Koh S, Ward SL, Lin M, Chen LS (2000) Sleep apnea treatment improves seizure control in children with neurodevelopmental disorders. Pediatr Neurol 22: 36-39.

209. Malow BA, Weatherwax KJ, Chervin RD, Hoban TF, Marzec ML, et al. (2003) Identification and treatment of obstructive sleep apnea in adults and children with epilepsy: a prospective pilot study. Sleep Med 4: 509-515.

210. Peppard PE, Young T, Palta M, Skatrud J (2000) Prospective study of the association between sleep-disordered breathing and hypertension. $\mathrm{N}$ Engl J Med 342: 1378-1384.

211. Trupp RJ, Hardesty P, Osborne J, Shelby S, Lamba S, et al. (2004) Prevalence of sleep disordered breathing in a heart failure program. Congest Heart Fail 10: 217-220.

212. Nieto FJ, Young TB, Lind BK, Shahar E, Samet JM, et al. (2000) Association of sleep-disordered breathing, sleep apnea, and hypertension 
in a large community-based study. Sleep Heart Health Study. JAMA 283 1829-1836.

213. Vaughn BV, D'Cruz OF, Beach R, Messenheimer JA (1996) Improvement of epileptic seizure control with treatment of obstructive sleep apnoea. Seizure 5: 73-78.

214. Wyler AR, Weymuller EA Jr (1981) Epilepsy complicated by sleep apnea. Ann Neurol 9: 403-404.

215. Sonka K, Juklícková M, Pretl M, Dostálová S, Horínek D, et al. (2000) Seizures in sleep apnea patients: occurrence and time distribution. Sb Lek 101: 229-232.

216. Beran RG, Holland GJ, Yan KY (1997) The use of CPAP in patients with refractory epilepsy. Seizure 6: 323-325.

217. Li P, Ghadersohi S, Jafari B, Teter B, Sazgar M (2012) Characteristics of refractory vs. medically controlled epilepsy patients with obstructive sleep apnea and their response to CPAP treatment. Seizure 21: 717-721.

218. Segal E, Vendrame M, Gregas M, Loddenkemper T, Kothare SV (2012) Effect of treatment of obstructive sleep apnea on seizure outcomes in children with epilepsy. Pediatr Neurol 46: 359-362.

219. Takhar J, Bishop J (2000) Influence of chronic barbiturate administration on sleep apnea after hypersomnia presentation: case study. J Psychiatry Neurosci 25: 321-324.

220. Lambert MV, Bird JM (1997) Obstructive sleep apnoea following rapid weight gain secondary to treatment with vigabatrin (Sabril). Seizure 6: 233-235.

221. Breum L, Astrup A, Gram L, Andersen T, Stokholm KH, et al. (1992) Metabolic changes during treatment with valproate in humans: implication for untoward weight gain. Metabolism 41: 666-670.

222. Dinesen H, Gram L, Andersen T, Dam M (1984) Weight gain during treatment with valproate. Acta Neurol Scand 70: 65-69.

223. Egger J, Brett EM (1981) Effects of sodium valproate in 100 children with special reference to weight. Br Med J (Clin Res Ed) 283: 577-581.

224. Hogan RE, Bertrand ME, Deaton RL, Sommerville KW (2000) Total percentage body weight changes during add-on therapy with tiagabine, carbamazepine and phenytoin. Epilepsy Res 41: 23-28.

225. Peppard PE, Young T, Palta M, Dempsey J, Skatrud J (2000) Longitudinal study of moderate weight change and sleep-disordered breathing. JAMA 284: 3015-3021.

226. Jalava M, Sillanpää M (1997) Physical activity, health-related fitness, and health experience in adults with childhood-onset epilepsy: a controlled study. Epilepsia 38: 424-429.

227. Steinhoff BJ, Neusüss K, Thegeder H, Reimers CD (1996) Leisure time activity and physical fitness in patients with epilepsy. Epilepsia 37: 1221-1227.

228. Mattson RH, Pratt KL, Calverley JR (1965) Electroencephalograms of epileptics following sleep deprivation. Arch Neurol 13: 310-315.

229. Pratt KL, Mattson RH, Weikers NJ, Williams R (1968) EEG activation of epileptics following sleep deprivation: a prospective study of 114 cases. Electroencephalogr Clin Neurophysiol 24: 11-15.

230. Stevens JR, Kodama H, Lonsbury B, Mills L (1971) Ultradian characteristics of spontaneous seizure discharges recorded by radio telemetry in man. Electroencephalogr Clin Neurophysiol 31: 313-325.

231. Gunderson CH, Dunne PB, Feyer TL (1973) Sleep deprivation seizures. Neurology 23: 678-686.

232. Ellingson RJ, Wilken K, Bennett DR (1984) Efficacy of sleep deprivation as an activation procedure in epilepsy patients. J Clin Neurophysiol 1: 83-101.

233. Civardi C, Collini A (2007) Sleep deprivation increases cortical excitability in epilepsy: syndrome-specific effects. Neurology 69: 318.

234. Badawy RA, Curatolo JM, Newton M, Berkovic SF, Macdonell RA (2006) Sleep deprivation increases cortical excitability in epilepsy: syndromespecific effects. Neurology 67: 1018-1022.

235. Fountain NB, Kim JS, Lee SI (1998) Sleep deprivation activates epileptiform discharges independent of the activating effects of sleep. J Clin Neurophysiol 15: 69-75.
236. Pokk P, Zharkovsky A (1995) The effects of drugs acting at GABAbenzodiazepine-barbiturate receptor complex on the behaviour of sleepdeprived mice. Pharmacol Toxicol 76: 23-28.

237. Malow BA, Passaro E, Milling C, Minecan DN, Levy K (2002) Sleep deprivation does not affect seizure frequency during inpatient video-EEG monitoring. Neurology 59: 1371-1374.

238. Rajna P, Veres J (1993) Correlations between night sleep duration and seizure frequency in temporal lobe epilepsy. Epilepsia 34: 574-579.

239. Kaleyias J, Cruz M, Goraya JS, Valencia I, Khurana DS, et al. (2008) Spectrum of polysomnographic abnormalities in children with epilepsy. Pediatr Neurol 39: 170-176.

240. Malow BA, Bowes RJ, Lin X (1997) Predictors of sleepiness in epilepsy patients. Sleep 20: 1105-1110.

241. Vendrame M, Auerbach S, Loddenkemper T, Kothare S, Montouris G (2011) Effect of continuous positive airway pressure treatment on seizure control in patients with obstructive sleep apnea and epilepsy. Epilepsia 52: e168-171.

242. Tirosh E, Tal Y, Jaffe M (1995) CPAP treatment of obstructive sleep apnoea and neurodevelopmental deficits. Acta Paediatr 84: 791-794.

243. Vgontzas AN, Bixler EO, Chrousos GP (2005) Sleep apnea is a manifestation of the metabolic syndrome. Sleep Med Rev 9: 211-224.

244. Gami AS, Howard DE, Olson EJ, Somers VK (2005) Day-night pattern of sudden death in obstructive sleep apnea. N Engl J Med 352: 1206-1214.

245. (1986) Adverse reactions to antiepileptic drugs: a multicenter survey of clinical practice. Collaborative Group for Epidemiology of Epilepsy. Epilepsia 27: 323-330.

246. Steriade M, McCormick DA, Sejnowski TJ (1993) Thalamocortical oscillations in the sleeping and aroused brain. Science 262: 679-685.

247. Oliveira AJ, Zamagni M, Dolso P, Bassetti MA, Gigli GL (2000) Respiratory disorders during sleep in patients with epilepsy: effect of ventilatory therapy on EEG interictal epileptiform discharges. Clin Neurophysiol 111 Suppl 2: S141-145.

248. Mitchell RB, Boss EF (2009) Pediatric obstructive sleep apnea in obese and normal-weight children: impact of adenotonsillectomy on quality-oflife and behavior. Dev Neuropsychol 34: 650-661.

249. Foldvary-Schaefer N, Stephenson L, Bingaman W (2008) Resolution of obstructive sleep apnea with epilepsy surgery? Expanding the relationship between sleep and epilepsy. Epilepsia 49: 1457-1459.

250. Bigal ME, Liberman JN, Lipton RB (2006) Obesity and migraine: a population study. Neurology 66: 545-550.

251. Adams JP, Murphy PG (2000) Obesity in anaesthesia and intensive care. Br J Anaesth 85: 91-108.

252. Chung SA, Yuan H, Chung F (2008) A systemic review of obstructive sleep apnea and its implications for anesthesiologists. Anesth Analg 107: 1543-1563.

253. Luo JJ, Dun NJ: New research advances in obesity: Relevant to neurologic disorders. Brain Disord Ther 2012; :1:e103.

254. Gallassi R (2006) Epileptic amnesic syndrome: an update and further considerations. Epilepsia 47 Suppl 2: 103-105.

255. Kapur N (1993) Transient epileptic amnesia--a clinical update and a reformulation. J Neurol Neurosurg Psychiatry 56: 1184-1190.

256. Thomas RJ (1997) Seizures and epilepsy in the elderly. Arch Intern Med 157: 605-617.

257. Logan W, Sherman DG (1983) Transient global amnesia. Stroke 14: 1005-1007.

258. Hodges JR, Warlow CP (1990) Syndromes of transient amnesia: towards a classification. A study of 153 cases. J Neurol Neurosurg Psychiatry 53: 834-843.

259. Fisher CM, Adams RD (1958) Transient global amnesia. Trans Amer Neurol Assoc 83:143-146.

260. Fisher CM, Adams RD (1964) Transient global amnesia. Acta Neurol Scand Suppl 40: SUPPL 9:1-83.

261. Fisher CM (1982) Transient global amnesia. Precipitating activities and other observations. Arch Neurol 39: 605-608. 
262. Bender MB (1960) Single episode of confusion with amnesia. Bull N Y Acad Med 36: 197-207.

263. Evans JH (1966) Transient loss of memory, an organic mental syndrome. Brain 89: 539-548.

264. Quinette P, Guillery-Girard B, Dayan J, de la Sayette V, Marquis S, et al. (2006) What does transient global amnesia really mean? Review of the literature and thorough study of 142 cases. Brain 129: 1640-1658.

265. Rowan AJ, Protass LM (1979) Transient global amnesia: clinical and electroencephalographic findings in 10 cases. Neurology 29: 869-872.

266. Li J, Hu WL (2013) Bilateral hippocampal abnormalities in magnetic resonance imaging in transient global amnesia. Am J Emerg Med 31: 755

267. Bartsch T, Butler C (2013) Transient amnesic syndromes. Nat Rev Neurol 9: 86-97.

268. Markowitsch HJ, Staniloiu A (2012) Amnesic disorders. Lancet 380: 1429-1440.

269. Midorikawa A, Kawamura M (2007) Recovery of long-term anterograde amnesia, but not retrograde amnesia, after initiation of an anti-epileptic drug in a case of transient epileptic amnesia. Neurocase 13: 385-389.

270. Shekhar R (2008) Transient global amnesia--a review. Int J Clin Pract 62: 939-942.

271. Chen ST, Tang LM, Hsu WC, Lee TH, Ro LS, et al. (1999) Clinical features, vascular risk factors, and prognosis for transient global amnesia in Chinese patients. J Stroke Cerebrovasc Dis 8: 295-299.

272. Pai MC (2000) Prolonged reversible amnesia: a case report. J Stroke Cerebrovasc Dis 9: 86-88

273. Palmini AL, Gloor P, Jones-Gotman M (1992) Pure amnestic seizures in temporal lobe epilepsy. Definition, clinical symptomatology and functional anatomical considerations. Brain 115: 749-769.

274. Rabinowicz AL, Starkstein SE, Leiguarda RC, Coleman AE (2000) Transient epileptic amnesia in dementia: a treatable unrecognized cause of episodic amnestic wandering. Alzheimer Dis Assoc Disord 14: 231-233.

275. Bilo L1, Meo R, Ruosi P, de Leva MF, Striano S (2009) Transient epileptic amnesia: an emerging late-onset epileptic syndrome. Epilepsia 50 Suppl 5: $58-61$.

276. Bradshaw J, Saling M, Hopwood M, Anderson V, Brodtmann A (2004) Fluctuating cognition in dementia with Lewy bodies and Alzheimer's disease is qualitatively distinct. J Neurol Neurosurg Psychiatry 75: 382-387.

277. Vercueil L, Hirsch E (2002) Seizures and the basal ganglia: a review of the clinical data. Epileptic Disord 4 Suppl 3: S47-54.

278. Sinforiani E, Manni R, Bernasconi L, Banchieri LM, Zucchella C (2003) Memory disturbances and temporal lobe epilepsy simulating Alzheimer's disease: a case report. Funct Neurol 18: 39-41.

279. Perucca E, Tomson T (2011) The pharmacological treatment of epilepsy in adults. Lancet Neurol 10: 446-456.

280. Glauser T, Ben-Menachem E, Bourgeois B, Cnaan A, Guerreiro C, et al. (2013) Updated ilae evidence review of antiepileptic drug efficacy and effectiveness as initial monotherapy for epileptic seizures and syndromes. Epilepsia 54: 551-563.

281. Martín P, Maestú F, Sola RG (2002) Effects of surgical treatment on intellectual performance and memory in a Spanish sample of drugresistant partial onset-temporal lobe epilepsy patients. Seizure 11: 151-156.

282. Sinclair DB, Aronyk K, Snyder T, McKean J, Wheatley M, et al. (2003) Pediatric temporal lobectomy for epilepsy. Pediatr Neurosurg 38: 195-205.

283. Sinclair DB, Aronyk KE, Snyder TJ, Wheatley BM, McKean JD, et al. (2003) Pediatric epilepsy surgery at the University of Alberta: 1988-2000. Pediatr Neurol 29: 302-311.

284. Drane DL, Meador KJ (2002) Cognitive and behavioral effects of antiepileptic drugs. Epilepsy Behav 3: 49-53.

285. Loring DW, Meador KJ (2001) Cognitive and behavioral effects of epilepsy treatment. Epilepsia 42 Suppl 8: 24-32.

286. Elger CE, Helmstaedter C, Kurthen M (2004) Chronic epilepsy and cognition. Lancet Neurol 3: 663-672.

287. Rausch R, Kraemer S, Pietras CJ, Le M, Vickrey BG, et al. (2003) Early and late cognitive changes following temporal lobe surgery for epilepsy. Neurology 60: 951-959.

288. 288. Blanchette N, Smith ML (2002) Language after temporal or frontal lobe surgery in children with epilepsy. Brain Cogn 48: 280-284. 